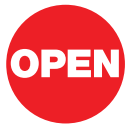

SUBJECT AREAS: ELECTROCHEMISTRY

BATTERIES

REACTION MECHANISMS

STRUCTURAL PROPERTIES

Received

14 October 2012

Accepted

29 October 2012

Published

3 December 2012

Correspondence and requests for materials should be addressed to Q.-H.Y. lyang. quanhong@mail.sz.

tsinghua.edu.cn; qhyangcn@tju.edu.cn) or F.Y.K. lfykang@ mail.tsinghua.edu.cn)

\section{Gassing in $\mathrm{Li}_{4} \mathrm{Ti}_{5} \mathrm{O}_{12}$-based batteries and its remedy}

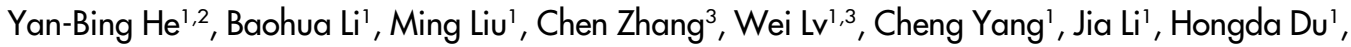 \\ Biao Zhang ${ }^{2}$, Quan-Hong Yang ${ }^{1,3}$, Jang-Kyo Kim² \& Feiyu Kang'
}

'Engineering Laboratory for Functionalized Carbon Materials and Key Laboratory of Thermal Management Engineering and Materials, Graduate School at Shenzhen, Tsinghua University, Shenzhen 518055, China, ${ }^{2}$ Department of Mechanical Engineering, Hong Kong University of Science and Technology, Clear Water Bay, Kowloon, Hong Kong, ${ }^{3}$ School of Chemical Engineering and Technology, Tianjin University, Tianjin 300072, China.

Destructive gas generation with associated swelling has been a major challenge to the large-scale application of lithium ion batteries (LIBs) made from $\mathrm{Li}_{4} \mathrm{Ti}_{5} \mathrm{O}_{12}$ (LTO) anodes. Here we report root causes of the gassing behavior, and suggest remedy to suppress it. The generated gases mainly contain $\mathrm{H}_{2}, \mathrm{CO}_{2}$ and $\mathrm{CO}$, which originate from interfacial reactions between LTO and surrounding alkyl carbonate solvents. The reactions occur at the very thin outermost surface of LTO (111) plane, which result in transformation from (111) to (222) plane and formation of (101) plane of anatase $\mathrm{TiO}_{2}$. A nanoscale carbon coating along with a stable solid electrolyte interface (SEI) film around LTO is seen most effective as a barrier layer in suppressing the interfacial reaction and resulting gassing from the LTO surface. Such an ability to tune the interface nanostructure of electrodes has practical implications in the design of next-generation high power LIBs.

ithium ion batteries (LIBs) have been widely applied in many electronic devices due to their high energy densities, flexible design, light weight and long lifespan compared to other types of batteries, such as $\mathrm{Ni}-\mathrm{Cd}$, $\mathrm{Ni}-\mathrm{MH}$ and lead acid batteries ${ }^{1,2}$. For the same reasons, they also have been considered as an excellent power source for electric vehicles (EVs) and energy storage stations (ESSs) that require high energy density, long cyclic life and excellent safety performance. At present, various forms of carbons are the dominant source of anode materials for $\mathrm{LIBs}^{3,4}$, which, however, have shown some critical issues, including poor cyclic life, high reactivity with electrolyte solution that easily contribute to the thermal runaways of battery under certain abusive conditions $s^{5}$. Myriad investigations have hitherto been conducted to develop new electrode materials that possess much improved electrochemical and safety performance ${ }^{6-8}$.

Spinel $\mathrm{Li}_{4} \mathrm{Ti}_{5} \mathrm{O}_{12}$ (LTO) anode has a theoretical capacity of $175 \mathrm{mAhg}^{-1}$ within the voltage range of $2.5 \sim 1.0 \mathrm{~V}$, and exhibits excellent reversibility due to its zero volume change during charge/discharge cycles. In addition, LTO demonstrates excellent safety and cyclic performance, making it a potential anode material for high power applications $^{9-11}$. Unfortunately, LTO shows a low intrinsic electronic conductivity and lithium-ion diffusion coefficient ${ }^{12,13}$, resulting in poor high-rate charge/discharge capabilities. A number of strategies, including carbon coating $^{14,15}$, metal and nonmetal ion doping ${ }^{13,16-18}$, hybridization with carbon and metal powders ${ }^{19-23}$, reduction in particle size ${ }^{24}$, and formation of micro-scale secondary particles consisting of nanostructured primary particles ${ }^{8,13}$, have been devised to improve the electrochemical performance of LTO anodes with varied success.

Even after a decade of tremendous efforts based on the above approaches ${ }^{25}$, however, LTO anode is not considered the most preferable choice for large-scale applications by the power LIB industries mainly due to severe gassing during charge/discharge cycles and storage, especially at elevated temperatures ${ }^{26,27}$. Gassing in leadacid batteries is known to be caused by overcharging or short circuits inside the battery ${ }^{28,29}$. However, gassing in LTO-based LIBs is little understood although it leads to serious swelling and hence becomes a grave safety concern, a main obstacle to widespread use of LTO-based batteries. The battery industries are expecting an effective remedy for the gassing problem so as to pave the way for the vast applications of LTO power battery in EVs and ESSs. To date, there are only a few reports that specifically refer to the gassing behavior of LTO electrodes ${ }^{26,27,30-32}$. Very recently, the gas generated inside the $\mathrm{LTO} / \mathrm{LiMn}_{2} \mathrm{O}_{4}$ cells has been confirmed to mainly consist of $\mathrm{H}_{2}, \mathrm{CO}_{2}$ and $\mathrm{CO}^{26}$. It is suggested that $\mathrm{H}_{2}$ is possibly derived from a trace of $\mathrm{H}_{2} \mathrm{O}$, while $\mathrm{CO}_{\text {and }} \mathrm{CO}_{2}$ result from the decomposition of electrolyte solution initiated at relatively high temperatures by $\mathrm{PF}_{5}$ that is a strong Lewis acid and one of the decomposition products of the electrolyte, $\mathrm{LiPF}_{6}{ }^{26,33-35}$. However, gassing always occurs even when the LTO-based battery is not cycled and only stored at room temperature. Moreover, commercial graphite anodes soaked in $\mathrm{LiPF}_{6}$ electrolyte do not show similar gassing behavior during storage or cyclic 
test under similar conditions. The above literature survey and practical operational experience clearly indicate that the underlying mechanisms for the formation of these gasses are still unclear, and the understanding of the roles of $\mathrm{LiPF}_{6}$ electrolyte in gassing reactions in LTO-based batteries is far from complete.

Here we aim to identify the root causes of gassing in LTO-based batteries, and hence to propose effective methods to control it. For these purposes, we designed five experimental conditions (see Table 1 for details). Conditions A, B and C are intended to identify whether the gassing reactions are initiated by $\mathrm{PF}_{5}$ or LTO. Conditions $\mathrm{D}$ and $\mathrm{E}$, which are encountered in the practical operation of LIBs, are respectively employed to evaluate gas generation process during storage (fully charged in the formation process) and cyclic tests of soft-packed LTO batteries. The comparative investigations on the above five conditions help reach an understanding of the root causes of the gassing behaviors, that is, interfacial reaction between LTO and electrolyte solution; note that not $\mathrm{PF}_{5}$ but LTO initiates such an interfacial reaction based the gassing process associated with a phase change and the formation of a new phase; and a carbon coating, functioning as a constructive barrier around LTO particles, is effective to suppress the gassing and the resultant swelling of commercial LTO-based batteries.

\section{Results}

Gassing behaviors under Conditions A-E. Nano-structured active materials have a high reactivity with electrolyte, making it very difficult to detect the intrinsic reactions taking place between the electrode and electrolyte. Therefore, micro-sized cubic LTO powders were synthesized to study the gassing reactions in this work. The particle size of LTO is $\sim 1 \mu \mathrm{m}$ as confirmed by the scanning electron microscopy (SEM) and transmission electron microscopy (TEM) observations (Supplementary Fig. S1a-b). The $\mathrm{X}$-ray diffraction (XRD) patterns of the LTO is in good agreement with the JCPDS standard (card No. 49-0207) and can be indexed to the spinel structure of LTO with the space group $F d 3 m$ (Supplementary Fig. S1c). Weak diffraction peaks of rutile $\mathrm{TiO}_{2}$ are detected, indicating an existence of small fraction of rutile $\mathrm{TiO}_{2}$ nano-coating that can improve the rate performance of $\mathrm{LTO}^{36}$.

The soft packed NCM/LTO batteries were assembled with $\mathrm{Li}\left(\mathrm{Ni}_{1 / 3} \mathrm{Co}_{1 / 3} \mathrm{Mn}_{1 / 3}\right) \mathrm{O}_{2}(\mathrm{NCM})$ as the cathode, the LTO prepared above as the anode, and $1 \mathrm{M} \mathrm{LiPF}_{6} / \mathrm{EC}+\mathrm{DMC}+\mathrm{EMC}$ as the electrolyte solution. Using such soft packed NCM/LTO batteries, the specific capacities of the LTO measured at the $1^{\text {st }}$ and $400^{\text {th }}$ cycles are 148.7 and $138.5 \mathrm{mAh} \mathrm{g}^{-1}$, respectively (Fig. 1a). It is noted that very obvious swelling is observed for the battery after cyclic test under Condition E (Fig. 1e-f). Even the fully charged battery that was only stored at $25^{\circ} \mathrm{C}$ for 3 months (Conditions D) also presents similar gassing behavior (Fig. 1c-d). It is apparent that the swelling results from the gas generated in the soft packed batteries. The rate of gassing gradually decreases with increasing the storage and cyclic period.
As presented above, five conditions were designed to simulate the gassing process between LTO and electrolyte (See Table 1 for details). Interestingly, obvious swelling also occur when $\mathrm{LTO}$ or rutile $\mathrm{TiO}_{2}$ is soaked in solvents (Condition A) or electrolyte solution (Condition B) (not subject to any electrochemical process), whereas there is no obvious swelling when there is only electrolyte solution in the absence of LTO or rutile $\mathrm{TiO}_{2}$ (Condition C). This difference can be clearly identified from the volume of gas generated under Conditions A, B and C (Fig. 2e). The above results indicate that the gassing behaviors are intimately related to LTO or rutile $\mathrm{TiO}_{2}$.

The gas components were analyzed by gas chromatograms and the results are summarized in Table 2 and Table S1. The gassing behaviors of LTO with electrolyte solution or solvent under different conditions are schematically depicted in Fig. $2 \mathrm{a}-\mathrm{d} . \mathrm{CO}_{2}$ is the only component generated when LTO is soaked under Conditions A and $\mathrm{B}$, whereas $\mathrm{H}_{2}, \mathrm{CO}_{2}, \mathrm{CO}$ and a trace of gaseous hydrocarbons are generated when the NCM/LTO batteries are stored (Condition D) and cycled (Condition $\mathrm{E}$ ) where $\mathrm{H}_{2}$ fraction is over $50 \mathrm{wt} \%$. Note that $\mathrm{H}_{2}$ and $\mathrm{CO}$ are generated in the batteries that were subjected to charge/discharge cyclic test, suggesting that the charged LTO promotes the generation of $\mathrm{H}_{2}$ and $\mathrm{CO}$ which are driven by electrochemical reactions.

$\mathrm{PF}_{5}$, a strong Lewis acid and one of the decomposition products of $\mathrm{LiPF}_{6}$, has been mistakenly considered as the major source of initiating the gassing reactions in the presence of trace amount of water ${ }^{26,33}$. In sharp contrast, our observation indicate that gassing always occurs even when LTO is soaked in solvents under Condition A (totally free from $\mathrm{LiPF}_{6}$ ) and $\mathrm{CO}_{2}$ is the only gas component (Fig. $2 \mathrm{e}$ and Supplementary Table $\mathrm{S} 1$ ). That is to say that $\mathrm{PF}_{5}$ originated from $\mathrm{LiPF}_{6}$ is not mainly responsible for the generation of $\mathrm{CO}_{2}{ }^{33,34}$. As discussed above, much less gassing occurs under Condition $\mathrm{C}$ (totally free from LTO or rutile $\mathrm{TiO}_{2}$ ) as compared to the cases under Conditions $\mathrm{A}$ and $\mathrm{B}$. It is therefore concluded that $\mathrm{CO}_{2}$ generation is mainly attributed to the intrinsic reaction between LTO or rutile $\mathrm{TiO}_{2}$ and alkyl carbonate solvents. Unexpectedly, the volume of gas generated of LTO or rutile $\mathrm{TiO}_{2}$ soaked under Condition A is obviously larger than that under Condition $\mathrm{B}$, although the component of gas is exactly the same $\left(\mathrm{CO}_{2}\right)$ (Fig. 2e). This further indicates that $\mathrm{LiPF}_{6}$ does not favor the gassing reactions, but rather suppresses it to a certain extent (details will be discussed below).

As is expected, the reactivity of solvents and electrolyte solutions with $\mathrm{LTO}$ or rutile $\mathrm{TiO}_{2}$ at $50^{\circ} \mathrm{C}$ is higher than that at $25^{\circ} \mathrm{C}$, which suggests that the higher temperature also promote the above reactions. This can explain why the LTO-based battery is easily swelling at high temperature. For the same reason, we discuss in details the LTO soaked in solvent or electrolytes at $50^{\circ} \mathrm{C}$ to image the gassing behaviors more distinctly.

The volume of the generated gas as demonstrated in Fig. 2e also indicates that the reactivity of rutile $\mathrm{TiO}_{2}$ with electrolyte is apparently lower than that of LTO counterpart. In view of the above findings and a very small amount of rutile $\mathrm{TiO}_{2}$ contained in LTO, the

Table 1 | Conditions A-E to study gassing reaction mechanisms of LTO electrodes

Conditions

Condition A

Condition B

Condition C

Condition D

Condition $\mathrm{E}$
Package containing LTO (or rutile $\mathrm{TiO}_{2}$ ) soaked in electrolyte-free solvents at 25 or $50^{\circ} \mathrm{C}$ for 3 months Package containing LTO (or rutile $\mathrm{TiO}_{2}$ ) soaked in electrolyte solution at 25 or $50^{\circ} \mathrm{C}$ for 3 months Electrolyte solution stored at 25 or $50^{\circ} \mathrm{C}$ for 3 months in absence of LTO

Fully charged soft-packed battery stored at $25^{\circ} \mathrm{C}$ for 3 months

Soft-packed battery cycled 400 times at $25^{\circ} \mathrm{C}$ at a charge/discharge rate of $0.5 \mathrm{C}$
Remarks

Ethylene carbonate (EC); Diethyl carbonate (DEC); Dimethyl carbonate (DMC); Ethylene methyl carbonate (EMC); Propylene carbonate (PC) $1 \mathrm{M} \mathrm{LiPF} 6 / \mathrm{EC}$; LiPFo/DEC; LiPFo/DMC; LiPF $/ \mathrm{EMC}_{6}$ LiPFo/PC; LiPF $6 /$ $\mathrm{EC}+\mathrm{DMC}+\mathrm{EMC}$

$1 \mathrm{MLiPF}_{6} / \mathrm{EC}+\mathrm{DMC}+\mathrm{EMC}$

NCM/LTO or NCM/(LTO/C) battery (see details in Experimental section) $1 \mathrm{M} \mathrm{LiPF} 6 / \mathrm{EC}+\mathrm{DMC}+\mathrm{EMC}$ is used as electrolyte solution Same as Condition D 

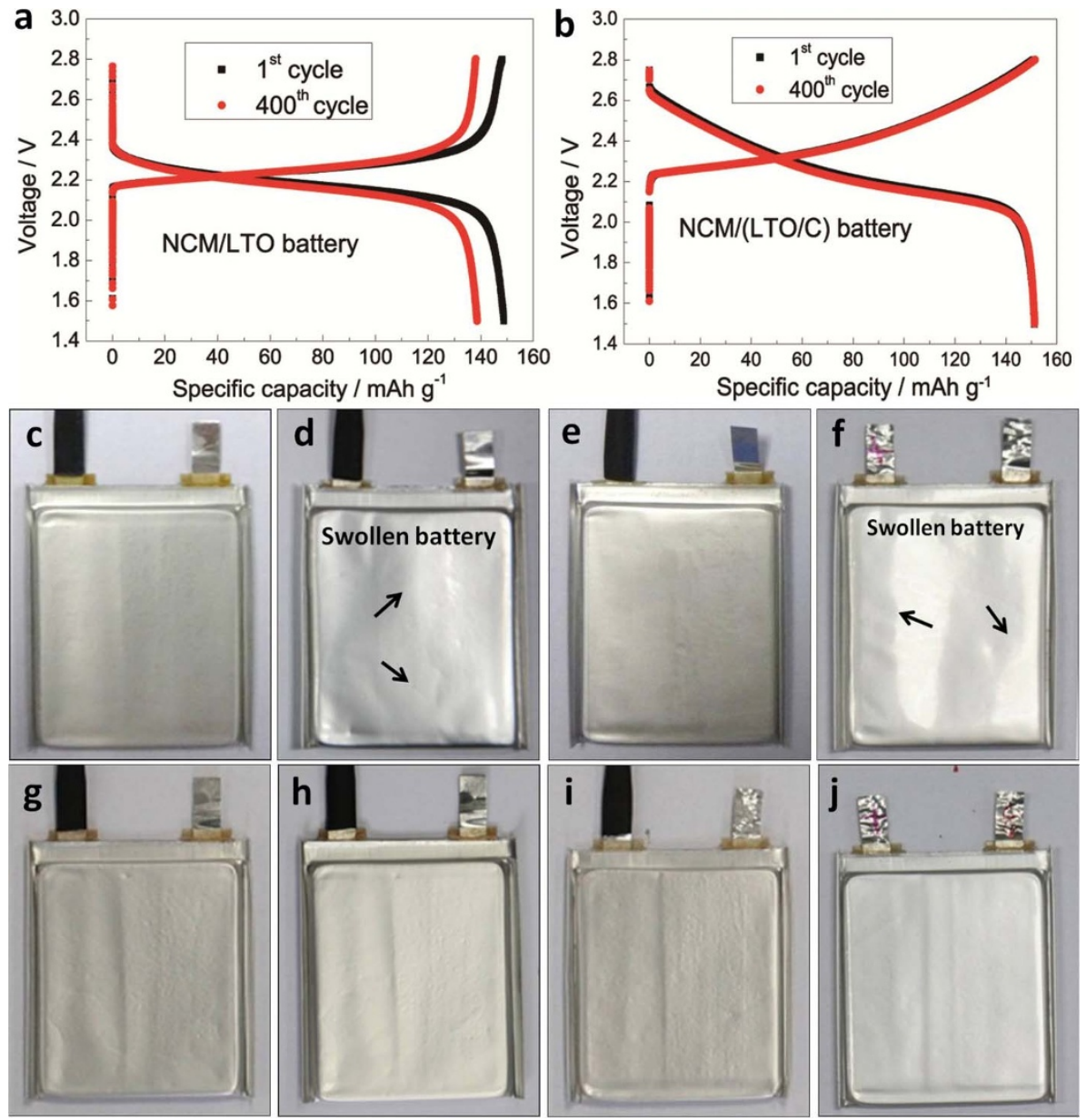

Figure 1 Cyclic and storage performance of NCM/LTO and NCM/(LTO/C) batteries under Conditions D and E. (a, b) Performance curves at 0.5C/ $0.5 \mathrm{C}$ and $25^{\circ} \mathrm{C}$ (Condition E). Photographs of soft-packed NCM/LTO batteries (c) before and (d) after storage under Condition D, and (e) before and (f) after cyclic test under Condition E. Photographs of soft-packed NCM/(LTO/C) batteries (g) before and (h) after storage under Condition D, and (i) before and (j) after cyclic test under Condition E. Note that swelling caused by gassing is observed in the NCM/LTO batteries (arrows ( $\uparrow$ ) labels the obviously swollen areas), but not in the $\mathrm{NCM} /(\mathrm{LTO} / \mathrm{C})$ batteries.

swelling of NCM/LTO batteries is mainly ascribed to the intrinsic reactions of LTO with electrolyte solution.

Carbon coating to suppress gassing in NCM/LTO battery. Here, carbon coating is employed as a thin barrier layer to control the gassing reaction by isolating the LTO particles from electrolyte solution. Carbon coated LTO (LTO/C) was prepared (see Methods) and its XRD pattern is in good agreement with the JCPDS file (card No. 49-0207) (Supplementary Fig. S3a). Low diffraction peaks of rutile and anatase $\mathrm{TiO}_{2}$ are observed and $\mathrm{LTO} / \mathrm{C}$ has a well-defined crystal structure with a particle size of around $300 \mathrm{~nm}$ (Supplementary Fig. S3b-e). The Raman spectra of LTO/C indicate that the carbon is mainly amorphous judging from the high the intensity ratio $\left(\mathrm{I}_{\mathrm{D}} / \mathrm{I}_{\mathrm{G}}=2.99\right)$ of $\mathrm{D}$ - and $\mathrm{G}$-band peaks (Supplementary Fig. S4a). Based on the thermogravimetric analysis (TGA), the carbon content is roughly estimated to be $\sim 3.0$ wt \% (Supplementary Fig. S4b).

The soft-packed NCM/(LTO/C) batteries were prepared using LTO/C as the anode and the specific capacities measured after the $1^{\text {st }}$ and $400^{\text {th }}$ cycles at $0.5 \mathrm{C} / 0.5 \mathrm{C}$ are $151.2 \mathrm{mAhg}^{-1}$ and $151.3 \mathrm{mAhg}^{-1}$, respectively (Fig. 1b). These values present much higher cyclic stability than the corresponding values of the uncoated LTO (Fig. 1a), testament to the beneficial effect of the carbon coating. In particular, no visible swelling occurs for the LTO/C-based battery after storage and cyclic test under both Conditions D and E (Fig. 1gj) unlike the uncoated LTO batteries (Fig.1c-f). This observation suggests that the carbon coating is very effective in suppressing the gassing behavior of LTO batteries.

Note that both the LTO and LTO/C-based batteries were prepared using the same condition. No apparent gassing occurs in the LTO/Cbased batteries, indicating that $\mathrm{H}_{2}$ is not generated in the LTO/Cbased batteries unlike the LTO-based batteries. This observation further hints that $\mathrm{H}_{2}$ generated in LTO-base batteries is not caused by the reactions of $\mathrm{Li}$ ions (or $\mathrm{Li}$ metal) with the trace $\mathrm{H}_{2} \mathrm{O}$ (or HF) that are present in both LTO-based and LTO/C-based batteries ${ }^{33}$. This means that the gassing based swelling of LTO-based batteries originates from the intrinsic reactions of electrolyte and LTO subjected to charge/discharge cyclic test.

Based on the above results, we can conclude that the gas generated in the swollen LTO-based batteries originates from the intrinsic reactions between the electrolyte solution and LTO, and is hardly related to $\mathrm{PF}_{5}$ and $\mathrm{H}_{2} \mathrm{O}$. In the next section, the gassing reaction mechanisms of LTO with electrolyte solution under different conditions are discussed in more detail and the role of carbon coating in suppressing the gassing behavior of LTO batteries is elucidated.

\section{Discussion}

Gassing processes of LTO in presence of alkyl carbonate solvents under different conditions are discussed in details as follows. LTO soaking in electrolyte-free solvent (DEC as a typical solvent for Condition A) is discussed at first. The original LTO has a welldefined crystal structure as indicated by the high-resolution TEM 

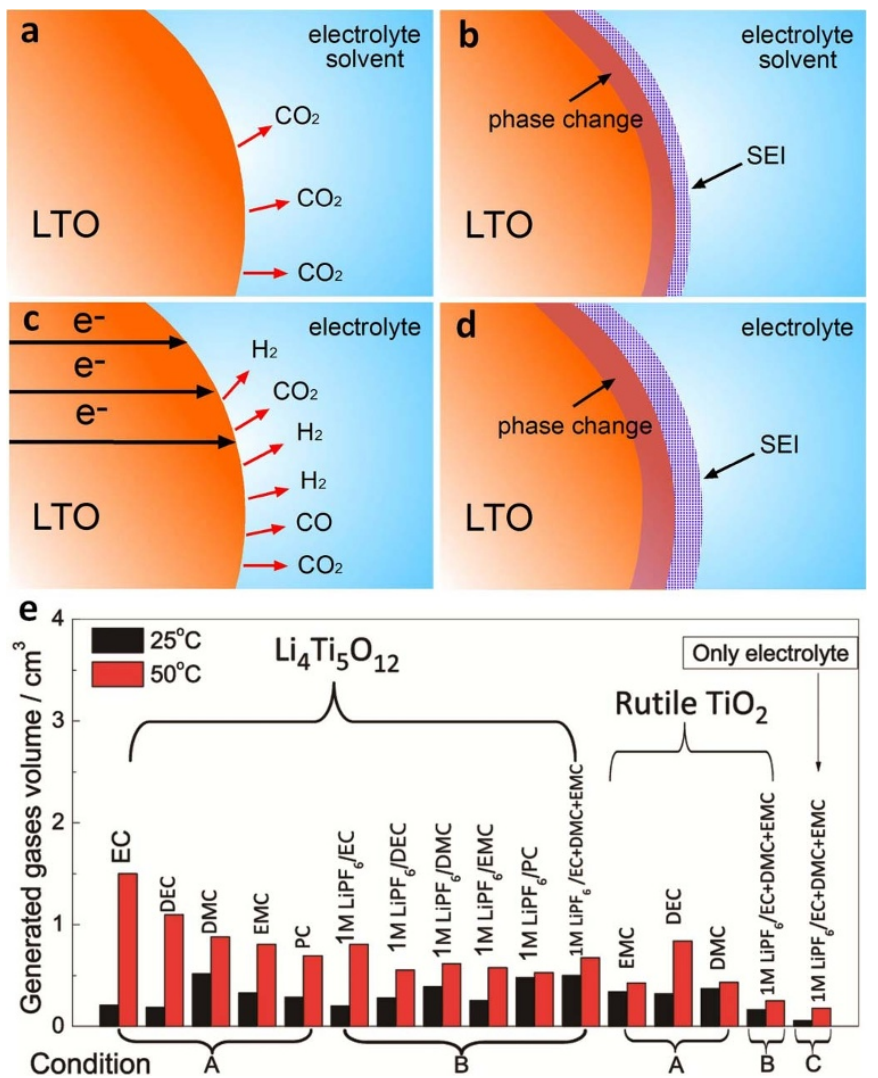

Figure $2 \mid$ Schematics of gassing behaviors of LTO electrodes with electrolyte under different conditions. (a) $\mathrm{CO}_{2}$ is generated when LTO is soaked under Conditions A and B. (b) The surface of LTO is covered by solid electrolyte interface (SEI) film consisting of the reaction products of LTO with solvents or electrolyte solution, and the phase change occurs at the outermost surface of LTO soaked under Conditions A and B. Note that the components of SEI film formed under Conditions A and B is obviously different. (c) Gaseous $\mathrm{H}_{2}, \mathrm{CO}_{2}$ and $\mathrm{CO}$ are generated when NCM/LTO batteries are stored and cycled under Conditions D and E. (d) The surface of LTO is covered by a SEI film consisting of the reaction products of LTO with electrolyte under Conditions $\mathrm{D}$ and $\mathrm{E}$, and phase change occurs at the outermost surface of LTO. Not that the thickness of SEI film under Conditions D and E are obviously different. (e) Volumes of gas generated when LTO or rutile $\mathrm{TiO}_{2}$ is soaked under Conditions A, B and C.

(HRTEM) image (Fig. 3a), and the $d$-spacing of $0.489 \mathrm{~nm}$ is in agreement with that of the (111) plane of spinel LTO. After LTO was soaked in DEC (totally free from $\mathrm{LiPF}_{6}$ as electrolyte), an apparent phase change occurs to the outermost surface and a very thin layer ( $3 \mathrm{~nm}$ in thickness) is unexpectedly formed around the LTO particles, which is totally different from the interior crystalline structure of the (111) plane (Fig. 3b) ${ }^{32}$. The $d$-spacing of the newly formed surface layer is $0.241 \mathrm{~nm}$ which matches well with that of the LTO (222) plane, indicating a transformation of the (111) plane to (222) plane at the outermost surface. Moreover, a new phase of the anatase $\mathrm{TiO}_{2}$ (101) plane with d-spacing of $0.357 \mathrm{~nm}$ is observed simultaneously (Fig. 3c). Judging from the absence of anatase $\mathrm{TiO}_{2}$ in the as-prepared LTO, the anatase $\mathrm{TiO}_{2}$ is also the result from soaking.

The Ti 2p and O 1s X-ray photoelectron spectroscopy (XPS) spectra of LTO obtained before and after soaking further prove the formation of $\mathrm{TiO}_{2}$ (Supplementary Fig. S5b and g). The C 1s spectrum of LTO after soaking presents three small typical peaks at 285.4, 286.5 and $288.9 \mathrm{eV}$, which can be assigned to $\mathrm{C}-\mathrm{C}, \mathrm{C}-\mathrm{O}$ and $\mathrm{O}-\mathrm{C}=\mathrm{O}$ groups (Supplementary Fig. S51), respectively ${ }^{37-39}$. The peak assigned to lithium carbonates $\left(\mathrm{Li}_{2} \mathrm{CO}_{3}\right.$ and $\left.\mathrm{ROCO}_{2} \mathrm{Li}\right)$ at $290.5 \mathrm{eV}$ is not detected ${ }^{38}$. Furthermore, only $\mathrm{CO}_{2}$ generated during soaking suggests that a decarboxylation reaction of DEC occurs at the interface between LTO and solvent.

The spinel crystallographic structure of LTO presents that the LTO (222) plane is composed only of $\left[\mathrm{Li}_{1 / 3} \mathrm{Ti}_{5 / 3}\right]$ layers, while the (111) plane is composed of $\mathrm{Li}^{+}, \mathrm{O}^{2-}$ and $\left[\mathrm{Li}_{1 / 3} \mathrm{Ti}_{5 / 3}\right]$ ions layers (Supplementary Fig. S7a-g). The plane transformation of LTO from (111) to (222) and the formation of anatase $\mathrm{TiO}_{2}$ suggest that the $\mathrm{Li}^{+}$ and $\mathrm{O}^{2-}$ ions at outermost surface of LTO are taken away during the interfacial reaction between LTO and DEC, which is associated with the generation of $\mathrm{CO}_{2}$ and the formation of a titanium-rich surface layer $^{32}$. The XRD patterns suggest that LTO maintains its spinel structure after soaking (Supplementary Fig. S8b) and there are no obvious anatase $\mathrm{TiO}_{2}$ peaks, indicating that only a very thin outermost surface layer of LTO takes part in the interfacial reaction and transforms to the anatase $\mathrm{TiO}_{2}$ (101) plane.

Therefore, the above discussion suggests that the decarboxylation reaction associated with $\mathrm{CO}_{2}$ generation is initiated by the terminated ions of LTO (111) plane, which results in the plane transformation from (111) to (222) and the formation of a new phase, anatase $\mathrm{TiO}_{2}$ (101) plane. The possible reaction mechanism is described in Figure $4 \mathrm{a}^{33}$ : the terminated $\mathrm{Ti}^{4+}$ ions of LTO coordinate with the unshared electron pairs of $\mathrm{O}^{2-}$ ions of carbonyl groups, while the outermost surface $\mathrm{O}^{2-}$ ions of LTO attack the carbon atom of $\mathrm{CH}_{3} \mathrm{CH}_{2} \mathrm{O}$ group and the flexible $\mathrm{Li}^{+}$ions coordinate with $\mathrm{O}^{2-}$ of $\mathrm{CH}_{3} \mathrm{CH}_{2} \mathrm{O}$ group. This reaction gives rise to the formation of $\mathrm{CO}_{2}$, $\mathrm{CH}_{3} \mathrm{COOLi}$, anatase $\mathrm{TiO}_{2}$ (101 plane) and $\mathrm{C}_{2} \mathrm{H}_{5} \mathrm{OC}_{2} \mathrm{H}_{5}$. The LTO is covered by a thin SEI film after soaking (Fig. 3b-c), which in turn separates the LTO from the surrounding DEC solvent and reduce to a certain extent the reactivity between LTO and solvent.

Similar gassing behaviors occur to LTO soaked in electrolyte solution (1 $\mathrm{M} \mathrm{LiPF}_{6} / \mathrm{EC}+\mathrm{DMC}+\mathrm{EMC}$ as an example for Condition $\left.\mathrm{B}\right)$. The XRD pattern and HRTEM images show that the anatase $\mathrm{TiO}_{2}$ (101) plane appeared in the LTO after soaking under Condition B (Figs $3 \mathrm{~d}$ and $5 \mathrm{c}$ ). However, both microstructure and surface chemistry of LTO are quite different under these two conditions (Supplementary Fig. S5h and $5 \mathrm{~m}$ ). Due to the existence of $\mathrm{LiPF}_{6}, \mathrm{Li}_{2} \mathrm{TiF}_{6}$ (JCPDS file of card No. 24-0662) was formed as a result of the reactions between $\mathrm{HF}$ and LTO (or anatase $\mathrm{TiO}_{2}$ ) (Fig. $\left.5 \mathrm{c}\right)^{26,40}$. In addition, a large amount of LiF (JCPDS file of card No. 04-0857) was formed on the surface of LTO, arising from the decomposition of $\mathrm{LiPF}_{6}$ at around $50^{\circ} \mathrm{C}$. The LTO surface was covered by $\mathrm{Li}_{2} \mathrm{TiF}_{6}$ and $\mathrm{LiF}$, making the reaction of LTO with surrounding solvents difficult. This is the main reason why the addition of $\mathrm{LiPF}_{6}$ in the solvents reduces the reactivity of LTO with electrolyte and somewhat retards the gassing reactions.

Table 2 | Gas generated for LTO soaked under Conditions A and B, and NCM/LTO batteries stored and cycled under Conditions D and E, respectively

\begin{tabular}{lccccccc} 
& $\mathrm{CO}_{2}$ wt\% & $\mathrm{H}_{2}$ wt\% & $\mathrm{CO} w+\%$ & $\mathrm{C}_{2} \mathrm{H}_{4}$ wt\% & $\mathrm{C}_{2} \mathrm{H}_{6}$ wt\% & $\mathrm{C}_{3} \mathrm{H}_{8}$ wt\% & $\mathrm{CH}_{4}$ wt\% \\
\hline Condition $\mathrm{A}$ & 100.00 & $/$ & $/$ & $/$ & $/$ & $/$ & $/$ \\
Condition B & 100.00 & $/$ & $/$ & $/$ & 1 & $/$ & 1 \\
Condition D & 30.41 & 55.65 & 10.00 & 2.09 & 1.10 & 0.32 & 0.43 \\
Condition E & 31.72 & 52.67 & 13.24 & $/$ & 1.34 & $/$ & 1.03 \\
\hline
\end{tabular}



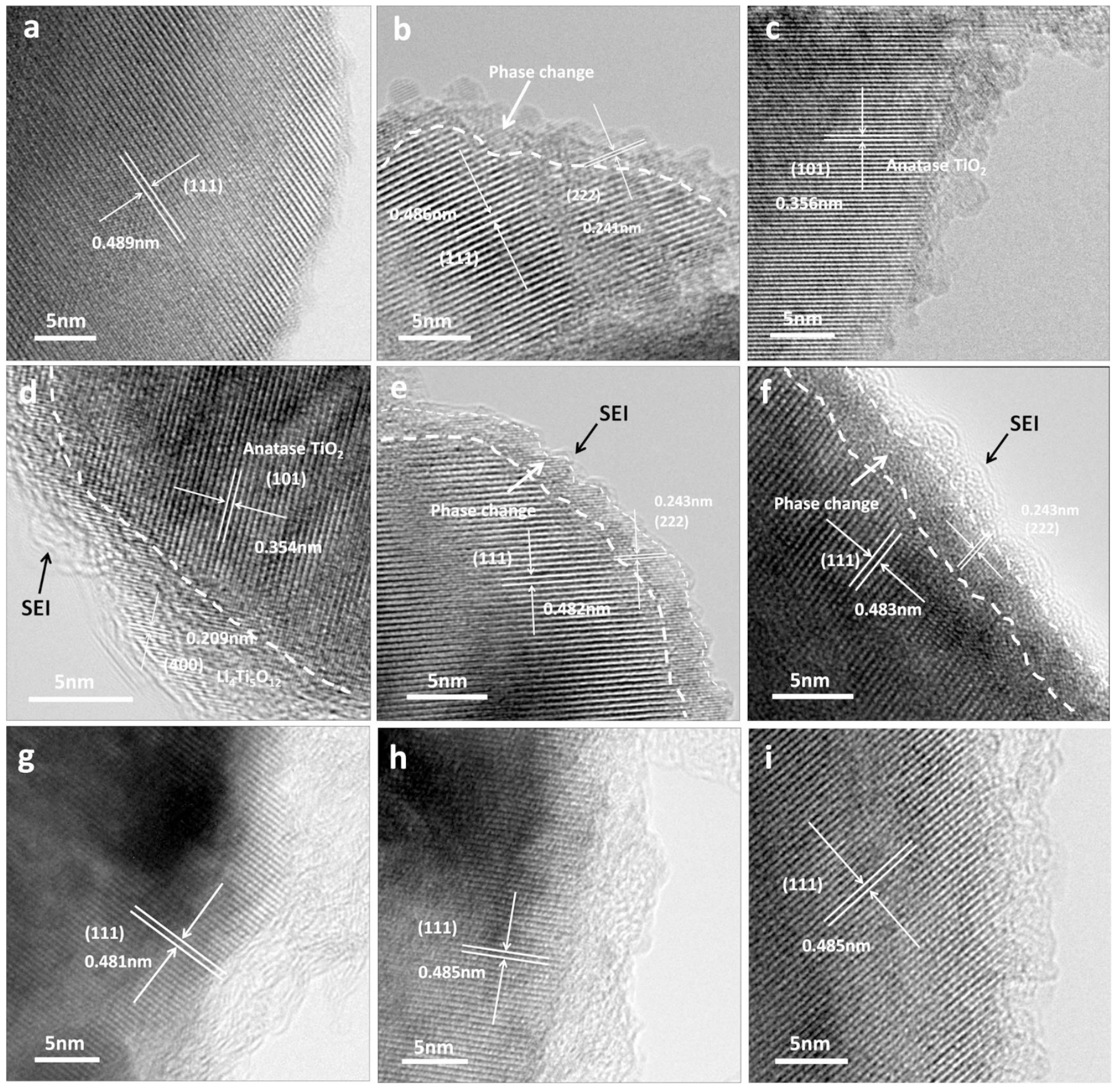

Figure 3 TEM images of LTO and LTO/C electrodes. (a) As-prepared LTO. (b, c) LTO soaked under Condition A (DEC at 50 ${ }^{\circ} \mathrm{C}$ ). (d) LTO soaked under Condition $\mathrm{B}\left(1 \mathrm{M} \mathrm{LiPF}_{6} / \mathrm{EC}+\mathrm{DMC}+\mathrm{EMC}\right.$ at $\left.50^{\circ} \mathrm{C}\right)$. (e) LTO in fully charged NCM/LTO battery stored under Condition D. (f) LTO in NCM/LTO battery cycled under Condition E. (g) As-prepared LTO/C. (h) LTO/C in fully charged NCM/(LTO/C) battery stored under Condition D. (i) LTO/C in $\mathrm{NCM} /(\mathrm{LTO} / \mathrm{C})$ battery cycled under Condition E. Note that the LTO and LTO/C batteries tested under Conditions D and E were fully discharged before TEM examination.

The O 1s XPS profile presents a large peak at $532.4 \mathrm{eV}$ which is assigned to $\mathrm{C}-\mathrm{O}-\mathrm{C}$ species, while two small peaks at 531.7 and $533.5 \mathrm{eV}$ are attributed to the $\mathrm{C}=\mathrm{O}$ species and the oxygen atom of lithium alkyl carbonates bounding to two carbon atoms, respectively $^{41,42}$ (Supplementary Fig. S5h). The C 1s detailed spectrum indicates that the $\mathrm{C}-\mathrm{O}$ species are the main reaction products between LTO and electrolyte solution. The peaks assigned to carbonates are hardly detected (Supplementary Fig. S5m). The FTIR spectrum (Supplementary Fig. S6d) of LTO after soaking presents three main peaks at $1634,1167 \mathrm{~cm}^{-1}$ and $1024 \mathrm{~cm}^{-1}$, which are associated with $\mathrm{C}=\mathrm{O}, \mathrm{C}-\mathrm{O}-\mathrm{C}$ and $\mathrm{ROLi}$ species, respectively, and these results are in accordance with the XPS results. Only $\mathrm{CO}_{2}$ is generated during LTO soaking under Condition $\mathrm{B}$ as a result of the decarboxylation reactions of solvents, similarly to Condition A (DEC). These reactions are also associated with the removal of $\mathrm{Li}^{+}$and $\mathrm{O}^{2-}$ ions at the outermost surface of LTO leading to the formation of (222) plane and anatase $\mathrm{TiO}_{2}$ (101) plane (Fig. 3d and Supplementary Fig. S8f). In view of the formation of many C-O-C species on the surface of LTO after soaking under Condition B, LTO may initiate the ring-opening polymerization of $\mathrm{EC}$, which results in the formation of $\mathrm{PEO}$-like oligomers $\left(-\mathrm{CH}_{2}-\mathrm{CH}_{2}-\mathrm{O}-\right)_{\mathrm{n}}$ and $\mathrm{CO}_{2}$ (Figure $\left.4 \mathrm{~b}\right)^{33,43}$.

The reacted surface of LTO is also covered by a SEI film with $\sim 2 \mathrm{~nm}$ in thickness resulting from the interfacial reaction, which is much thicker than that of LTO soaked under Condition A 


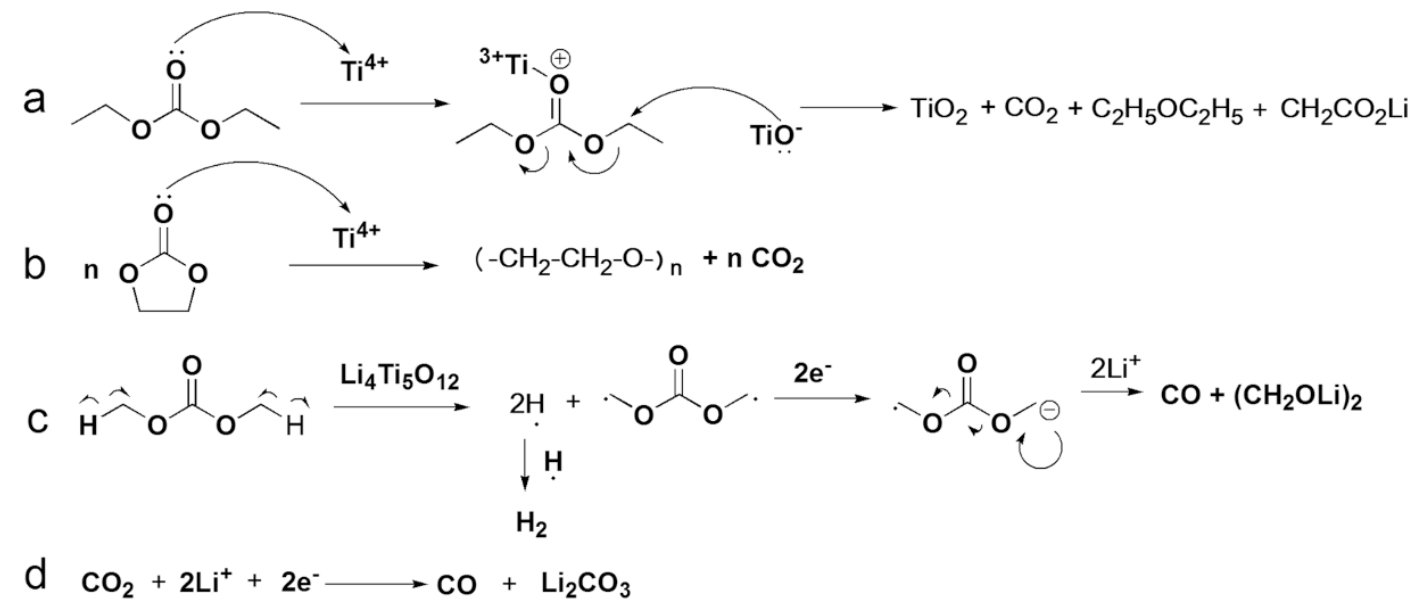

Figure 4 | Tentative gas generation reactions in the gassing of LTO electrode.
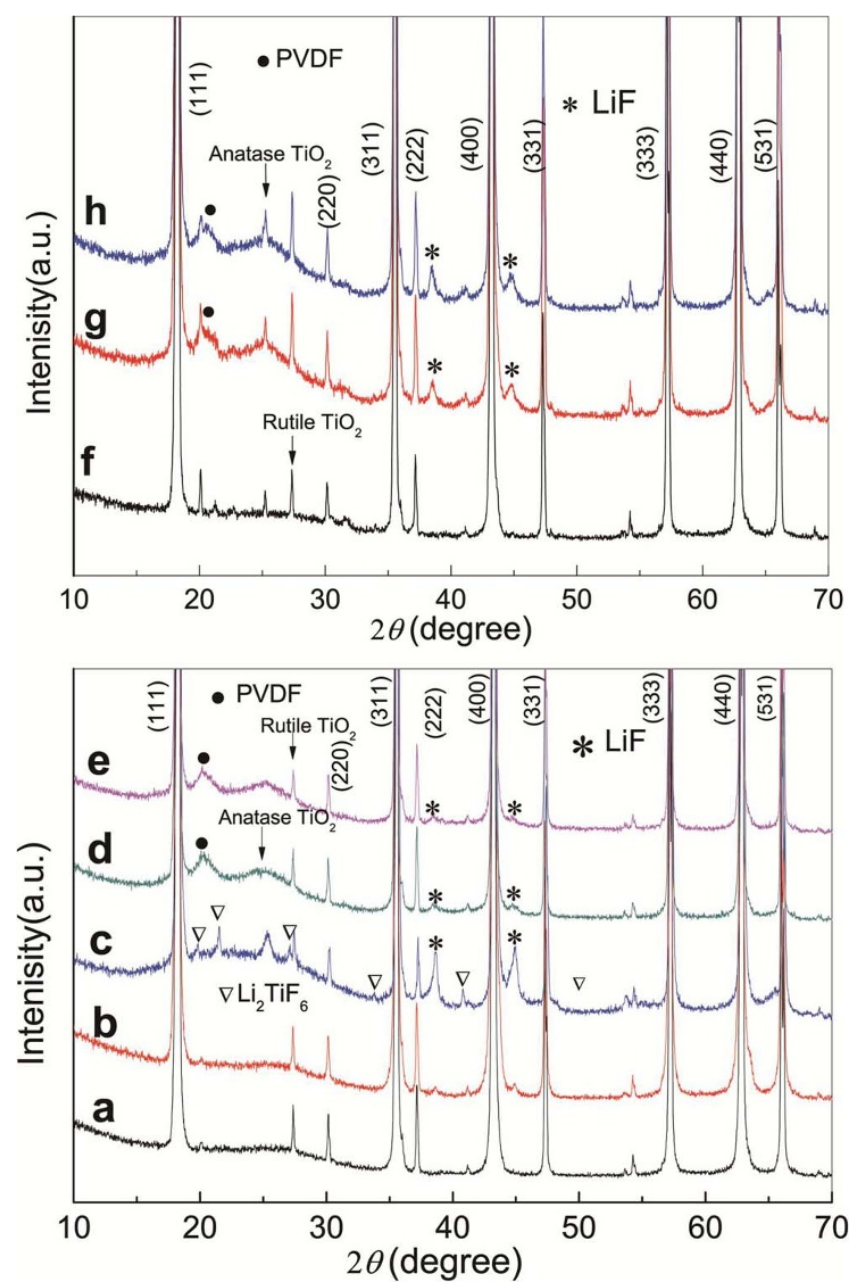

Figure $5 \mid$ XRD patterns of LTO and LTO/C. (a) As-prepared LTO. (b) LTO after soaking under Condition A (DEC at $\left.50^{\circ} \mathrm{C}\right)$. (c) LTO after soaking under Condition $\mathrm{B}\left(1 \mathrm{MLiPF}_{6} / \mathrm{EC}+\mathrm{DMC}+\mathrm{EMC}\right.$ at $\left.50^{\circ} \mathrm{C}\right)$.

(d) LTO in fully charged NCM/LTO battery stored under Condition D. (e) LTO in NCM/LTO battery cycled under Condition E. (f) As-prepared LTO/C. (g) LTO/C in fully charged NCM/(LTO/C) battery stored under Condition D. (h) LTO/C in NCM/(LTO/C) battery cycled under Condition E. Note that the NCM/LTO and NCM/(LTO/C) batteries tested under Conditions $\mathrm{D}$ and $\mathrm{E}$ were fully discharged before the XRD analysis.
(Fig. 3b). Based on the above analysis, the components and the thickness of the SEI film formed at the surface of LTO under Condition B are quite different from that subjected to Condition $\mathrm{A}$. With the exception of the decomposition products of solvents, $\mathrm{Li}_{2} \mathrm{TiF}_{6}$ and $\mathrm{LiF}$ formed on LTO under Condition B can further separate the LTO from the surrounding solvents thereby leading to an obviously less reactivity of LTO in electrolyte solution than in $\mathrm{LIPF}_{6}$-free solvents.

After NCM/LTO batteries were subjected to storage and cyclic tests (Conditions D and E), similar gassing behaviors were found as expected. The (111) plane at the outermost surface of LTO transforms to (222) plane, which is covered by a thin SEI film formed by the products derived from the interfacial reaction between LTO and electrolyte solution when LTO batteries were subjected to Conditions $\mathrm{D}$ and $\mathrm{E}$ (Fig. $3 \mathrm{e}-\mathrm{f}$ ). The thicknesses of the phase-change layers (from (111) to (222) plane) for LTOs under both conditions (storage and cyclic test) are almost the same $(\sim 3 \mathrm{~nm})$, which are, interestingly, similar to that of the LTO soaked under Condition A. It is thought that the phase-change occurs only in a very thin surface layer $(\sim 3 \mathrm{~nm})$. As discussed above, the phase change is attributed to the loss of $\mathrm{Li}^{+}$and $\mathrm{O}^{2-}$ ions from the (111) plane by the interfacial reactions between LTO and electrolyte solution. Both the phasechange surface along with newly formed (222) plane and the SEI film formed on top of the phase-change surface become the barrier to separate the LTO from the surrounding electrolyte solution, which can restrain the further interfacial reactions and loss of $\mathrm{Li}^{+}$and $\mathrm{O}^{2-}$ ions from the interior part of LTO. Therefore, it is said that the interfacial reactions between LTO and electrolyte solution mainly occur at the early stage of the storage or cyclic test. As such, the gassing rate gradually decreases as storage and cyclic test continue.

The XRD patterns show that the LTO electrodes tested under Condition $\mathrm{D}$ or $\mathrm{E}$ maintain the original spinel structure (Supplementary Fig. S8c). However, the XPS (Ti 2p and O 1s) spectra offer no information for unreacted LTO, a strong evidence of the reacted LTO particles being covered completely by the SEI film of reaction products (Supplementary Fig. S5d-e and S5i-j). The detailed XPS results ( $\mathrm{C} 1 \mathrm{~s}$ ) and FTIR spectra indicate that the $\mathrm{C}-\mathrm{O}$ species are the main components of the SEI film on LTO after storage and cyclic test, which is similar to that of LTO soaked under Condition B (Supplementary Figs S5m-o and S6e-f).

However, it should be mentioned that the formation mechanism of SEI film on LTO electrode is totally different from that on graphite anode. The formation of SEI film on graphite anode is attributed to the reduction reaction of electrolyte solution $(\sim 0.7 \mathrm{~V})$ along with gassing and $\mathrm{Li}_{2} \mathrm{CO}_{3}$ and $\mathrm{ROCO}_{2} \mathrm{Li}$ are the main components ${ }^{44,45}$. Because the reduction potential of most solvents is $\sim 0.7 \mathrm{~V}$, the 
reduction reaction of electrolyte solution occurs rapidly when the graphite anode is discharged to below $0.7 \mathrm{~V}$. Thus, the formation of SEI film only occurs in the first several cycles during the battery formation and stops in the following cycling. After formation, the gassing behavior stops in the graphite anode battery due to a stable and complete SEI film can separate the graphite from electrolyte solution and suppress the reduction decomposition of electrolyte.

In contrast, the formation of SEI film on LTO is resulted from the interfacial reactions between LTO and electrolyte solution, not the reduction of the electrolyte solution. The rate of interfacial reactions in LTO batteries is much lower than that of the reduction reaction of electrolyte solution in graphite-based batteries, and therefore a complete SEI film cannot be formed on LTO electrode during the battery formation process like the case of graphite electrode. Thus, the interfacial reaction further occurs during battery cycling test and longterm storage, which results in the continuous gas-release. The SEI film on LTO electrode is formed gradually with the processing of interfacial reaction, which leads to the decrease in the continuous gassing rate of LTO based battery accordingly. Moreover, the SEI film formed on the surface of LTO after the cyclic test under Condition E is much thicker than that LTO after storage under Condition D. It is well-known that the electrolyte solution is consumed during the battery cyclic tests gradually increasing the SEI film thickness.

Gases such as $\mathrm{H}_{2}, \mathrm{CO}_{2}$ and $\mathrm{CO}$ were generated under both Conditions $\mathrm{D}$ and $\mathrm{E}$. $\mathrm{CO}_{2}$ is derived from the decarboxylation reactions of solvents, similarly to Conditions A and B. As discussed above, $\mathrm{H}_{2}$ does not arise from the reactions of $\mathrm{Li}$ ions (or lithium metal) with $\mathrm{H}_{2} \mathrm{O}$ (or HF). The alkyl groups in alkyl carbonate are the only species that can provide the $\mathrm{H}$ proton in the battery. Therefore, the dehydrogenation of the alkoxy group in solvents may be promoted by LTO subjected to charge/discharge cycles and are responsible for the generation of $\mathrm{H}_{2}$. The intermediates of solvent dehydrogenation can further accept electrons and $\mathrm{Li}$ ions leading to the decarbonylation reactions and generation of $\mathrm{CO}^{46}$. The possible reaction mechanism is described in Figure 4c. $\mathrm{CO}_{2}$ can also be reduced to form $\mathrm{CO}$ according to Figure $4 \mathrm{~d}^{33,46-48}$. Therefore, it can be concluded that the LTO electrodes induce decarbonylation, decarboxylation and dehydrogenation reactions of solvents, directly accountable for gassing in LTO batteries.

Carbon coating around LTO is found as an effective method to suppress the gassing behavior of NCM/LTO batteries. The $d$-spacing measured from the HRTEM image of the as-prepared LTO/C is $0.481 \mathrm{~nm}$ (Fig. 3g), which matches well with the (111) plane of spinel LTO. The HRTEM images suggest that the LTO surface (e.g. the (111), (222) and (400) planes) is covered by a $\sim 5 \mathrm{~nm}$ thick carbon layer (Fig.3g and Supplementary Fig. S3d-e).

The XRD patterns of LTO/C after cyclic and storage tests (Conditions D and $\mathrm{E}$ ) indicate the formation of LiF, which was absent in the cases of the uncoated LTO electrode as discussed above (Fig. $5 \mathrm{~d}-\mathrm{e}$ and $5 \mathrm{~g}-\mathrm{h}$ ). The formation of $\mathrm{LiF}$ as an important SEI component is thought to be the consequence of the reaction between $\mathrm{PF}_{5}$ and $\mathrm{Li}_{2} \mathrm{CO}_{3}$ that is easily formed on the coated carbon surface during the battery first charge/discharge cycle, as reported previously ${ }^{44}$, and can stabilize the interface of carbon and electrolyte. In addition, the electric conductance of electrode is highly improved by the coating carbon. It is well-known that the formation of SEI film requires many electrons for decomposition of electrolyte solution. Thus, the high conductance of coating carbon favors an excellent and complete SEI formation, which can further protect the LTO from interfacial reactions.

The XPS spectra (O 1s and $\mathrm{C} 1 \mathrm{~s})$ and FTIR spectra of LTO electrodes indicate that the $\mathrm{RCO}_{3} \mathrm{Li}, \mathrm{C}-\mathrm{O}-\mathrm{C}$, and ROLi species in the SEI film were formed on the surface of LTO/C after battery storage (Condition D) and cyclic test (Condition E) (Supplementary Figs. S6h-i and S10g-h and k-1). That is, the carbon coating together with the stable SEI film formed on top of the carbon coating as a barrier layer may offer significant synergy to protect the LTO electrode from the surrounding electrolyte solution, eliminating the possible interfacial gassing reaction ${ }^{49}$.

The HRTEM images exhibited that the morphologies of the interface between LTO and carbon coating hardly changed under Conditions $\mathrm{D}$ and $\mathrm{E}$, proving a stable interface existing between them (Fig. 3h-i). Therefore, it can be said that carbon coating is an effective strategy to fully suppress the interfacial reaction and gassing on the LTO surface.

In summary, the gassing phenomenon in LTO electrodes has been one of the most serious obstacles to their large-scale applications in LIBs. $\mathrm{PF}_{5}$, as a strong Lewis acid of decomposition product of $\mathrm{LiPF}_{6}$, has been erroneously regarded as a major source for gassing in the presence of trace amount of water. This paper clarifies that the gassing reactions, including decarboxylation, decarbonylation and dehydrogenation reactions of solvents, are initiated not by $\mathrm{PF}_{5}$, but by LTO on the outermost surface of LTO (111) plane. The interfacial reactions between LTO and electrolyte solution generate gasses like $\mathrm{H}_{2}, \mathrm{CO}_{2}$ and $\mathrm{CO}$, which are the main sources for swelling of battery pack. The gassing involves the plane transformation of LTO from (111) to (222) and the formation of (101) plane of anatase $\mathrm{TiO}_{2}$ and the outermost surface $\mathrm{Li}^{+}$and $\mathrm{O}^{2-}$ ions of the LTO (111) plane are removed from LTO by the interfacial reactions.

Constructing a barrier layer is an effective strategy to control the interfacial reactions between LTO and the surrounding electrolyte solution, and a nanoscale carbon coating on LTO is proven to suppress the gassing of LTO batteries. The coated carbon, together with the stable SEI film formed around the coating offer significant synergy to separate LTO from the surrounding electrolyte solution and prevent the interfacial gassing reactions. The modification of LTO surface is a simple yet very effective strategy, which can both improve the high-rate charge/discharge performance of batteries and suppress the gassing behavior of LTO battery.

\section{Methods}

Synthesis of rutile $\mathrm{TiO}_{2}$, LTO and LTO/C. Rutile $\mathrm{TiO}_{2}$ was obtained by sintering the precursor amorphous $\mathrm{TiO}_{2}$ at $900^{\circ} \mathrm{C}$ for $8 \mathrm{~h}$. The LTO powder was synthesized by solid-state reaction of the mixture containing amorphous $\mathrm{TiO}_{2}$ with $\mathrm{Li}_{2} \mathrm{CO}_{3}$ in air. The $\mathrm{TiO}_{2}$ and $\mathrm{Li}_{2} \mathrm{CO}_{3}$ were mixed at a $\mathrm{Li}$ :Ti molar ratio of 4.2:5. Carbon coated LTO (LTO/C) composites were also prepared based on a similar solid-state reaction using the precursor mixture plus glucose in argon atmosphere. The details of the synthesis route can be found elsewhere $e^{49,50}$.

Preparation of soft-packed NCM/LTO batteries. Commercial 034352 type soft packed NCM/LTO batteries, of dimensions $3 \mathrm{~mm}$ thick, $43 \mathrm{~mm}$ wide and $52 \mathrm{~mm}$ long, were assembled to investigate the gassing behaviors of LTO batteries. The batteries were made of $\mathrm{Li}\left(\mathrm{Ni}_{1 / 3} \mathrm{Co}_{1 / 3} \mathrm{Mn}_{1 / 3}\right) \mathrm{O}_{2}$ (NCM) (Tianjiao Technology, Shenzhen, China) as the cathode, as- prepared LTO or LTO/C as the anode, polyethylene as the separator, and $1 \mathrm{M} \mathrm{LiPF}_{6} / \mathrm{EC}+\mathrm{DMC}+\mathrm{EMC}$ as the electrolyte solution. The NCM cathode consisted of 85 wt.\% NCM, 9 wt.\% Super-P and 6 wt.\% poly(vinylidene fluoride)(PVDF) binder, whereas the LTO anode consisted of 80 wt.\% LTO, 10 wt.\% Super-P and 10 wt.\% PVDF. These components were rolled together to form the battery core and assembled into aluminum-plastic laminated film packages. Batteries were charged and discharged three times between 1.5 and $2.8 \mathrm{~V}$ at a rate of $0.5 \mathrm{C}$ for stabilization before storage and cyclic tests under Conditions $\mathrm{D}$ and $\mathrm{E}$.

Gassing behaviors (Conditions A-E). As demonstrated in Table 1, five different conditions were designed to clarify the root causes of the gassing behaviors and the gases generated under all these conditions were analyzed on a gas chromatograph (Agilent 7890A GC System) using the GB/T 9722-2006 method.

Conditions A and B: LTO (or rutile $\mathrm{TiO}_{2}$ ) soaked in electrolyte-free solvent or electrolyte solution. $1.6 \mathrm{~g}$ of LTO or rutile $\mathrm{TiO}_{2}$ powders was put into aluminumplastic laminated film packages, and $4 \mathrm{~mL} \mathrm{LiPF}_{6}$-free solvent or $\mathrm{LiPF}_{6}$-based electrolyte solution was added before sealing of the packages in an argon-filled glove box (See Table 1 for details of the solvents and electrolytes used). The electrode packages were stored at 25 or $50^{\circ} \mathrm{C}$ for 3 months. The volumes of the packages before and after storage were monitored using the water displacement method. 
Condition C. Electrolyte solution ( $\left.1 \mathrm{M} \mathrm{LiPF}_{6} / \mathrm{EC}+\mathrm{DMC}+\mathrm{EMC}\right)$ stored at 25 or $50^{\circ} \mathrm{C}$ for 3 months in the absence of LTO. This condition is designed to evaluate the role of $\mathrm{LiPF}_{6}$ in the gassing reactions.

Condition D: Storage test of soft-packed NCM/LTO or NCM/(LTO/C) batteries. The assembled fully charged batteries were stored at $25^{\circ} \mathrm{C}$ for 3 months.

Condition E: Cyclic test of soft-packed NCM/LTO or NCM/(LTO/C) batteries. The assembled batteries were measured for 400 cycles at a charge/discharge rate of $0.5 \mathrm{C}(0.5 \mathrm{C} / 0.5 \mathrm{C})$ at $25^{\circ} \mathrm{C}$.

Characterization of structure and morphology changes of LTO and LTO/C under different conditions. The LTO and LTO/C electrode materials were rinsed after tests using DMC to remove the electrolyte and dried in the glove box antechamber to remove the residual DMC. XRD patterns of the samples were obtained on a diffractometer (Rigaku D/max 2500/PC) using $\mathrm{Cu} \mathrm{K} \alpha$ radiation. The morphologies were examined using a TEM (JOEL JEM-2100F, Japan). XPS measurements were conducted using Physical Electronics PHI5802 instrument using X-rays magnesium anode (monochromatic $\mathrm{K} \alpha \mathrm{X}$-rays at $1253.6 \mathrm{eV}$ ) as the source. The $\mathrm{C} 1 \mathrm{~s}$ region was used as a reference and was set at $284.8 \mathrm{eV}$.

1. Tarascon, J.-M. \& Armand, M. Issues and challenges facing rechargeable lithium batteries. Nature 414, 359-367 (2001).

2. Dunn, B., Kamath, H. \& Tarascon, J. M. Electrical Energy Storage for the Grid: A Battery of Choices. Science 334, 928-935 (2011).

3. Kaskhedikar, N. A. \& Maier, J. Lithium Storage ion Carbon Nanostructures. $A d v$. Mater. 21, 2664-2680 (2009)

4. Liu, C., Li, F., Ma, L. P. \& Cheng, H. M. Advanced Materials for Energy Storage. Adv. Mater. 22, E28-E62 (2010).

5. Spotnitz, R. \& Franklin, J. Abuse behavior of high-power, lithium-ion cells. J. Power Sources 113, 81-100 (2003).

6. Jung, H. G., Jang, M. W., Hassoun, J., Sun, Y. K. \& Scrosati, B. A high-rate long-life $\mathrm{Li}_{4} \mathrm{Ti}_{5} \mathrm{O}_{12} / \mathrm{Li}\left[\mathrm{Ni}_{0.45} \mathrm{Co}_{0.1} \mathrm{Mn}_{1.45}\right] \mathrm{O}_{4}$ lithium-ion battery. Nat. Commun 2 (516), 511-515 (2011).

7. Kang, K. S., Meng, Y. S., Breger, J., Grey, C. P. \& Ceder, G. Electrodes with high power and high capacity for rechargeable lithium batteries. Science 311, 977-980 (2006).

8. Amine, K. et al. Nanostructured Anode Material for High-Power Battery System in Electric Vehicles. Adv. Mater. 22, 3052-3057 (2010).

9. Ferg, E., Gummow, R. J., Kock, A. d. \& Thackeray, M. M. Spinel Anodes for Lithium-Ion Batteries. J. Electrochem. Soc. 141, L147-L150 (1994).

10. Ohzuku, T., Ueda, A. \& Yamamoto, N. Zero-Strain Insertion Material of $\mathrm{Li}\left[\mathrm{Li}_{1 / 3} \mathrm{Ti}_{5 / 3}\right] \mathrm{O}_{4}$ for Rechargeable Lithium Cells. J. Electrochem. Soc. 142, 1431-1435 (1995).

11. Aldon, L. et al. Chemical and Electrochemical Li-Insertion into the $\mathrm{Li}_{4} \mathrm{Ti}_{5} \mathrm{O}_{12}$ Spinel. Chem. Mater. 16, 5721-5725 (2004).

12. $\mathrm{Li}, \mathrm{B}$. H. et al. Facile synthesis of $\mathrm{Li}_{4} \mathrm{Ti}_{5} \mathrm{O}_{12} / \mathrm{C}$ composite with super rate performance. Energy Environ. Sci. 5, 9595-9602 (2012).

13. Zhao, L., Hu, Y. S., Li, H., Wang, Z. X. \& Chen, L. Q. Porous $\mathrm{Li}_{4} \mathrm{Ti}_{5} \mathrm{O}_{12}$ Coated with $\mathrm{N}$-Doped Carbon from Ionic Liquids for Li-Ion Batteries. Adv. Mater. 23, 1385-1388 (2011)

14. Wang, G. J. et al. Preparation and characteristic of carbon-coated $\mathrm{Li}_{4} \mathrm{Ti}_{5} \mathrm{O}_{12}$ anode material. J. Power Sources 174, 1109-1112 (2007).

15. Zhu, G.-N. et al. Carbon-coated nano-sized $\mathrm{Li}_{4} \mathrm{Ti}_{5} \mathrm{O}_{12}$ nanoporous micro-sphere as anode material for high-rate lithium-ion batteries. Energy Environ. Sci. 4 , 4016-4022 (2011)

16. Park, K. S., Benayad, A., Kang, D. J. \& Doo, S. G. Nitridation-Driven Conductive $\mathrm{Li}_{4} \mathrm{Ti}_{5} \mathrm{O}_{12}$ for Lithium Ion Batteries. J. Am. Chem. Soc. 130, 14930-14931 (2008).

17. Ji, S. Z. et al. Preparation and effects of Mg-doping on the electrochemical properties of spinel $\mathrm{Li}_{4} \mathrm{Ti}_{5} \mathrm{O}_{12}$ as anode material for lithium ion battery. Mater. Chem. Phys. 123, 510-515 (2010)

18. Tian, B., Xiang, H., Zhang, L., Li, Z. \& Wang, H. Niobium doped lithium titanate as a high rate anode material for Li-ion batteries. Electrochim. Acta 55, 5453-5458 (2010)

19. Huang, S. H., Wen, Z. Y., Zhu, X. J. \& Gu, Z. H. Preparation and electrochemical performance of $\mathrm{Ag}$ doped $\mathrm{Li}_{4} \mathrm{Ti}_{5} \mathrm{O}_{12}$. Electrochem. Commun. 6, 1093-1097 (2004).

20. Li, X., Qu, M. Z., Huai, Y. J. \& Yu, Z. L. Preparation and electrochemical performance of $\mathrm{Li}_{4} \mathrm{Ti}_{5} \mathrm{O}_{12} /$ carbon/carbon nano-tubes for lithium ion battery. Electrochim. Acta 55, 2978-2982 (2010).

21. Li, X., Qu, M. Z. \& Yu, Z. L. Preparation and electrochemical performance of $\mathrm{Li}_{4} \mathrm{Ti}_{5} \mathrm{O}_{12} /$ graphitized carbon nanotubes composite. Solid State Ionics 181, 635-639 (2010).

22. Cai, R., Yu, X., Liu, X. \& Shao, Z. $\mathrm{Li}_{4} \mathrm{Ti}_{5} \mathrm{O}_{12} / \mathrm{Sn}$ composite anodes for lithium-ion batteries: Synthesis and electrochemical performance. J. Power Sources 195, 8244-8250 (2010).

23. Zhang, B. et al. Urchin-like $\mathrm{Li}_{4} \mathrm{Ti}_{5} \mathrm{O}_{12}$-carbon nanofiber composites for high rate performance anodes in Li-ion batteries. J. Mater. Chem. 22, 12133-12140 (2012).

24. Borghols, W. J. H., Wagemaker, M., Lafont, U., Kelder, E. M. \& Mulder, F. M. Size Effects in the $\mathrm{Li}_{4+\mathrm{x}} \mathrm{Ti}_{5} \mathrm{O}_{12}$ Spinel. J. Am. Chem. Soc. 131, 17786-17792 (2009).

25. Zhu, G. N., Wang, Y. G. \& Xia, Y. Y. Ti-based compounds as anode materials for Li-ion batteries. Energy Environ. Sci. 5, 6652-6667 (2012).
26. Belharouak, I. et al. Performance Degradation and Gassing of $\mathrm{Li}_{4} \mathrm{Ti}_{5} \mathrm{O}_{12} / \mathrm{LiMn}_{2} \mathrm{O}_{4}$ Lithium-Ion Cells. J. Electrochem. Soc. 8, A1165-A1170 (2012).

27. Wu, K., Yang, J., Zhang, Y., Wang, C. \& Wang, D. Investigation on $\mathrm{Li}_{4} \mathrm{Ti}_{5} \mathrm{O}_{12}$ batteries developed for hybrid electric vehicle. J Appl Electrochem. DOI 10.1007/ s10800-012-0442-0 (2012).

28. Yang, Z. et al. Electrochemical Energy Storage for Green Grid. Chem. Rev. 111, 3577-3613 (2011).

29. Hammouche, A., Karden, E., Walter, J. \& Doncker, R. W. D. On the impedance of the gassing reactions in lead-acid batteries. J. Power Sources 96, 106-112 (2001).

30. Du Pasquier, A., Plitz, I., Menocal, S. \& Amatucci, G. A comparative study of Liion battery, supercapacitor and nonaqueous asymmetric hybrid devices for automotive applications. J. Power Sources 115, 171-178 (2003).

31. Ding, Z. J. et al. Towards understanding the effects of carbon and nitrogen-doped carbon coating on the electrochemical performance of $\mathrm{Li}_{4} \mathrm{Ti}_{5} \mathrm{O}_{12}$ in lithium ion batteries: a combined experimental and theoretical study. PCCP 13, 15127-15133 (2011).

32. Lu, X. et al. Lithium Storage in $\mathrm{Li}_{4} \mathrm{Ti}_{5} \mathrm{O}_{12}$ Spinel: The Full Static Picture from Electron Microscopy. Adv. Mater. 24, 3233-3238 (2012).

33. $\mathrm{Xu}, \mathrm{K}$. Nonaqueous liquid electrolytes for lithium-based rechargeable batteries. Chem. Rev. 104, 4303-4417 (2004).

34. Sloop, S. E., Pugh, J. K., Wang, S., Kerr, J. B. \& Kinoshita, K. Chemical Reactivity of $\mathrm{PF}_{5}$ and $\mathrm{LiPF}_{6}$ in Ethylene Carbonate/Dimethyl Carbonate Solutions. Electrochem. Solid-State Lett. 4, A42-A44 (2001).

35. Sloop, S. E., Kerr, J. B. \& Kinoshita, K. The role of Li-ion battery electrolyte reactivity in performance decline and self-discharge. J. Power Sources 119-121, 330-337 (2003)

36. Wang, Y.-Q. et al. Rutile- $\mathrm{TiO}_{2}$ Nanocoating for a High-Rate $\mathrm{Li}_{4} \mathrm{Ti}_{5} \mathrm{O}_{12}$ Anode of a Lithium-Ion Battery. J. Am. Chem. Soc. 134, 7874-7879 (2012).

37. Leroy, S., Martinez, H., Dedryvere, R., Lemordant, D. \& Gonbeau, D. Influence of the lithium salt nature over the surface film formation on a graphite electrode in Li-ion batteries: An XPS study. Appl. Surf. Sci. 253, 4895-4905 (2007).

38. Dedryvere, R. et al. Electrode/Electrolyte Interface Reactivity in High-Voltage Spinel $\mathrm{LiMn}_{1.6} \mathrm{Ni}_{0.4} \mathrm{O}_{4} / \mathrm{Li}_{4} \mathrm{Ti}_{5} \mathrm{O}_{12}$ Lithium-Ion Battery. J Phys Chem C 114, 10999-11008 (2010).

39. Dedryvere, R. et al. Characterization of lithium alkyl carbonates by X-ray photoelectron spectroscopy: Experimental and theoretical study. J. Phys. Chem. B 109, 15868-15875 (2005)

40. Janz, G. J., Lorenz, M. R. \& Brown, C. T. Preparation and Thermal Stability of Lithium Titanium Fluoride. J. Am. Chem. Soc. 80, 4126-4128 (1958)

41. Alfarra, A., Frackowiak, E. \& Beguin, F. Mechanism of lithium electrosorption by activated carbons. Electrochim. Acta 47, 1545-1553 (2002).

42. Zhang, J. H., Maurer, F. H. J. \& Yang, M. S. In situ Formation of $\mathrm{TiO}_{2}$ in Electrospun Poly(methyl methacrylate) Nanohybrids. J Phys Chem C 115, 10431-10441 (2011).

43. Dedryvere, R. et al. XPS identification of the organic and inorganic components of the electrode/electrolyte interface formed on a metallic cathode. J. Electrochem. Soc. 152, A689-A696 (2005).

44. Dedryvère, R. et al. Surface film formation on electrodes in a $\mathrm{LiCoO}_{2} /$ graphite cell: A step by step XPS study. J. Power Sources 174, 462-468 (2007).

45. Wang, Y. X., Nakamura, S., Ue, M. \& Balbuena, P. B. Theoretical studies to understand surface chemistry on carbon anodes for lithium-ion batteries: Reduction mechanisms of ethylene carbonate. J. Am. Chem. Soc. 123, 11708-11718 (2001)

46. Yoshida, H. et al. Degradation mechanism of alkyl carbonate solvents used in lithium-ion cells during initial charging. J. Power Sources 68, 311-315 (1997).

47. Aurbach, D. et al. The Correlation between the Surface-Chemistry and the Performance of Li-Carbon Intercalation Anodes for Rechargeable Rocking-Chair Type Batteries. J. Electrochem. Soc. 141, 603-611 (1994).

48. Aurbach, D., Markovsky, B., Weissman, I., Levi, E. \& Ein-Eli, Y. On the correlation between surface chemistry and performance of graphite negative electrodes for $\mathrm{Li}$ ion batteries. Electrochim. Acta 45, 67-86 (1999).

49. He, Y. B. et al. Carbon coating to suppress the reduction decomposition of electrolyte on the $\mathrm{Li}_{4} \mathrm{Ti}_{5} \mathrm{O}_{12}$ electrode. J. Power Sources 202, 253-261 (2012).

50. Ning, F. et al. Effects of $\mathrm{TiO}_{2}$ crystal structure on the performance of $\mathrm{Li}_{4} \mathrm{Ti}_{5} \mathrm{O}_{12}$ anode material. J. Alloys Compd. 513, 524-529 (2012).

\section{Acknowledgements}

We thank Y. Chen for valuable discussions about reactions Scheme and N. Y. Tang, D. Y. Zhai for valuable comments for this work, and we also thank Dongguan Amperex Technology Limited for the help in gas components analysis. This work was supported by National Nature Science Foundation of China (Nos. 51072131, 51202121 and 51232005), Shenzhen Projects for Basic Research (Nos. JC201104210152A and JCYJ20120619152808478), Guangdong Province Innovation R\&D Team Plan for Energy and Environmental Materials (No.2009010025).

\section{Author contributions}

Q.-H.Y. and F.Y.K. conceived the project and Y.-B.H., B.H.L. and Q.-H.Y. designed the experiments. Y.-B.H. B.H.L. and M.L. carried out the materials synthesis, battery assembly 
and gases components analysis. C.Z., W.L. and B.Z. performed the structural characterization and components analysis. J.L. constructed the crystal structure model. Y.-B.H., Q.-H.Y., B.H.L., C.Y., H.D.D., J.-K.K. and F.Y.K. discussed the results. Y.-B.H., Q.-H.Y., J.-K.K. and F.Y.K. wrote the initial manuscript which was approved by all the authors.

\section{Additional information}

Supplementary information accompanies this paper at http://www.nature.com/ scientificreports
Competing financial interests: The authors declare no competing financial interests. License: This work is licensed under a Creative Commons

Attribution-NonCommercial-NoDerivs 3.0 Unported License. To view a copy of this license, visit http://creativecommons.org/licenses/by-nc-nd/3.0/

How to cite this article: $\mathrm{He}, \mathrm{Y}$. et al. Gassing in $\mathrm{Li}_{4} \mathrm{Ti}_{5} \mathrm{O}_{12}$-based batteries and its remedy. Sci. Rep. 2, 913; DOI:10.1038/srep00913 (2012). 